\title{
Development of a europium nanoparticles lateral flow immunoassay for NGAL detection in urine and diagnosis of acute kidney injury
}

\author{
Moli Yin', Yuanwang Nie², Hao Liu², Lei Liu', Lu Tang ${ }^{1}$, Yuan Dong ${ }^{2}$, Chuanmin Hu and Huiyan Wang ${ }^{1 *}$
}

\begin{abstract}
Background: AKI is related to severe adverse outcomes and mortality with Coronavirus Disease 2019 (COVID-19) patients, that early diagnosed and intervened is imperative. Neutrophil gelatinase-associated lipocalin (NGAL) is one of the most promising biomarkers for detection of acute kidney injury (AKI), but current detection methods are inadequacy, so more rapid, convenient and accuracy methods are needed to detect NGAL for early diagnosis of AKI. Herein, we established a rapid, reliable and accuracy lateral flow immunoassay (LFIA) based on europium nanoparticles (EU-NPS) for the detection of NGAL in human urine specimens.

Methods: A double-antibody sandwich immunofluorescent assay using europium doped nanoparticles was employed and the NGAL monoclonal antibodies (MAbs) conjugate as labels were generated by optimizing electric fusion parameters. Eighty-three urine samples were used to evaluate the clinical application efficiency of this method.

Results: The quantitative detection range of NGAL in AKI was 1-3000 ng/mL, and the detection sensitization was $0.36 \mathrm{ng} / \mathrm{mL}$. The coefficient of variation (CV) of intra-assay and inter-assay were $2.57-4.98 \%$ and $4.11-7.83 \%$, respectively. Meanwhile, the correlation coefficient between europium nanoparticles-based lateral fluorescence immunoassays (EU-NPS-LFIA) and ARCHITECT analyzer was significant $\left(R^{2}=0.9829, n=83, p<0.01\right)$.

Conclusions: Thus, a faster and easier operation quantitative assay of NGAL for AKI has been established, which is very important and meaningful to diagnose the early AKl, suggesting that the assay can provide an early warning of final outcome of disease.
\end{abstract}

Keywords: neutrophil gelatinase-associated lipocalin (NGAL), monoclonal antibody, lateral flow immunoassay, acute kidney injury (AKI)

\footnotetext{
*Correspondence: jlmpcwhy@163.com

'Jilin Collaborative Innovation Center for Antibody Engineering, Jilin Medical University, 132013 Jilin, PR China

Full list of author information is available at the end of the article
}

(c) The Author(s). 2022 Open Access This article is licensed under a Creative Commons Attribution 4.0 International License, which permits use, sharing, adaptation, distribution and reproduction in any medium or format, as long as you give appropriate credit to the original author(s) and the source, provide a link to the Creative Commons licence, and indicate if changes were made. The images or other third party material in this article are included in the article's Creative Commons licence, unless indicated otherwise in a credit line to the material. If material is not included in the article's Creative Commons licence and your intended use is not permitted by statutory regulation or exceeds the permitted use, you will need to obtain permission directly from the copyright holder. To view a copy of this licence, visit http://creativecommons.org/licenses/by/4.0/. The Creative Commons Public Domain Dedication waiver (http://creativecommons.org/publicdomain/zero/1.0/) applies to the data made available in this article, unless otherwise stated in a credit line to the data. 


\section{Background}

Coronavirus Disease 2019 (COVID-19) has widely spread in the worldwide scale with serious disaster[1].Acute kidney injury (AKI) has a higher rate of morbidity and mortality in common complication for critical illnesses and counted about 5-7 \% of hospitalized patients in world[2].Several studies have evaluated the development of AKI is more strongly related to worse outcomes and mortality rates of COVID-19, described incidence of AKI that ranges widely from 0.5 to $36.6 \%$ in COVID- 19 patient$\mathrm{s}[3]$.Early detection and precise treatments of AKI can implement better preventive strategies and prevent deterioration of renal function and renal failure, effectively contain progression of the COVID-19 hospitalized patients[4]. Among them, neutrophil gelatinase-associated lipocalin (NGAL) has been recognized as one of the promising biomarkers candidate for detection of AKI. NGAL is a $25 \mathrm{kDa}$ glycoprotein associated with gelatinase from neutrophil and usually exist at lower level in human tissues such as stomach, colon and kidney, but its expression is dramatical increased in serum and urine when the kidney was with ischemic or nephrotoxic injury[5].

Lateral flow immunoassays (LFIA) has been regard as desired screening assays on account of simplicity, in-situ analysis and easy to work[6]. The LFIA with fluorescent microparticles have already been used for detection of various microbial pathogens and several inflammation markers $[7,8]$. Several novel nanoparticles have been generally applied to improve the sensitivity of LFIA, including carbon nanoparticles, quantum dots, fluorescent dyes, magnetic nanolabels and europium nanoparticles (EU-NPS)[9]. EU-NPS as carriers can improve 100-fold sensitivity contrast with colloidal gold nanoparticles labeled in LFIA[10]. EU-NPS are long fluorescence lifetime and also available with an average particle size of 75-100 nm range, the large Stokes shift of which is usually over $200 \mathrm{~nm}$ is conducive to avoid the interference of scattered light caused by measuring excitation light. EU-NPS have wide excitation band so that it is beneficial to increase the excitation energy, the sharp emission peak, low background and high resolution, used in sandwich-type immunoassays of medical diagnostics recently[11].

Here, we established a new method with EU-NPS as labels of LFIA for the rapid, sensitive and early measurement of NGAL in urine based on two monoclonal antibodies (MAbs) $1 \mathrm{G} 1$ and 2F4 which are discoveried by our lab. The method is double-antibody sandwich immunofluorescent assay using EU-NPS and MAbs conjugate as labels. The mAb 1G1 was conjugated with EU-NPS and the mAb 2F4 was used to capture EU-NPS-1G1-antigen complex in T-line. Our results showed that EU-NPS-LFIA could be used for the early NGAL detection in urine and allow improvement in the treatment of AKI patients.

\section{Methods}

\section{Expression and purification of NGAL}

The human NGAL gene sequence from Genbank (NP 005555.2) was synthesized by Beijing Institute of Genomics (BGI) and added restriction enzymes HindIII and $\mathrm{XhoI}$ at both ends. The plasmids were digested with Hin$d \mathrm{III}$ and XhoI, and then cloned into the pSecTag2A vector. The constructed plasmids were sequenced to confirm without mutation, and then transformed into Chinese Hamster Ovary $(\mathrm{CHO})$ cells by the Lipofectami$n \mathrm{e}^{\mathrm{TM}} 2000$. After 8 days, the cell supernatant was collected after filtering $0.45 \mu \mathrm{m}$ filter. The expressed NGAL- $6 \times$ His protein was purified with the Nickel Nitrilotriacetic Acid (Ni-NTA) column, and the different fractions were collected and appraised by sodium dodecyl sulfate-polyacrylamide gel electrophoresis (SDSPAGE). The bicinchoninic acid (BCA) Protein Quantification Kit measured the concentration of protein.

The purified recombinant protein was subjected in $12 \%$ SDS-PAGE, then adsorbed onto a polyvinylidene fluoride (PVDF) membrane. After the membrane was blocked in tris buffer with $1 \%$ Tween-20 (TBST) solution containing $5 \%$ skimmed milk at room temperature (RT) for $2 \mathrm{~h}$, incubated with HRP-conjugated anti- $6 \times$ His tag antibody (1:5000) in the dark for $1 \mathrm{~h}$ at RT, visualized with Benzidine after washed with TBST and visualized by Bio-Rad Western blotting detection system (DNR Bio-Imaging Systems Ltd., Israel).

\section{Generation and purification of MAbs}

In the first immunization, the female BALB/c mice (age of 6 weeks, a total of 10) were immunized with $50 \mu \mathrm{g}$ NGAL- $6 \times$ His recombinant protein emulsified in equal dosage of complete Freund's adjuvant, and accessional immunized were accomplished with protein emulsified in incomplete Freund's adjuvant. Two hypodermic injections on the back of mice and subsequent were intraperitoneal injections spaced 21 days. The serum samples were collected one week after the third injection, and the titre of antiserum was determined with indirect enzyme-linked immunosorbent assay (ELISA)[12]. Three days before fusion, mice were performed to booster immunization with $50 \mu \mathrm{g}$ of NGAL-6xHis diluted with $0.9 \% \mathrm{NaCl}$.

The isolated immune mice spleen cells and the SP2/0 myeloma cells mixed at a ratio of 3:1 to fuse in a platinum electrode LF498-3 fusion chamber (BEX Co., Ltd, Japan) as described literature[13]. Briefly, the mixed cell was washed twice with $10 \mathrm{~mL}$ electrofusion buffer (0.3 M mannitol, $0.1 \mathrm{mM} \mathrm{CaCl}, 0.1 \mathrm{mM} \mathrm{MgCl}_{2}, \mathrm{pH}$ 7.2 ), re-suspended at a concentration of $2 \times 10^{7}$ cells/ $\mathrm{mL}$. The fusion was completed using an alternating current voltage of $50 \mathrm{~V}$ at $0.8 \mathrm{MHz}$ for $20 \mathrm{~s}$, direct current pulse voltage of $450 \mathrm{~V}$ of 2 repetitions for $0.5 \mathrm{~s}$, 
and post-fusion was $50 \mathrm{~V}$ at $0.8 \mathrm{MHz}$ for $7 \mathrm{~s}$. Finally, the electric-treated cell suspension was moved from the fusion chamber into $4.5 \mathrm{~mL}$ of preheated RPMI 1640 ( $20 \%$ fetal bovine serum) for $30 \mathrm{~min}$ at $37^{\circ} \mathrm{C}$, then cultured in 96-well plates and incubated with $5 \% \mathrm{CO}_{2}$ at $37^{\circ} \mathrm{C}$. After $24 \mathrm{~h}$, hypoxanthine-aminopterin-thymidine (HAT) was supplemented to each well. The Cell culture supernatants were screened by ELISA after 9 days fusion, and calculated number of hybridoma clones. The $\mathrm{BALB} / \mathrm{c}$ mice which injected with paraffin oil in advance were inoculated with $1 \times 10^{6}$ of NGAL hybridoma cells, the ascites were purified by Protein A column.

\section{Identification of MAbs}

The immunoglobulin subclasses of antibodies were analyzed using the antibody subclass identification kit. The indirect ELISA screened the specific MAbs by using purified recombinant NGAL- $6 \times$ His protein and PCT$6 \times$ His protein. The interaction between antigen and antibodies were determined with BIAcore T200 system (GE Healthcare, Stockholm, Sweden) in HBS-EP buffer (0.005\% surfactant P20, $10 \mathrm{mM}$ Hepes, pH 7.4, 3 mM EDTA, $150 \mathrm{mM} \mathrm{NaCl}$ ). The NGAL antigen was adsorbed on CM5 biosensor chips reaching 400-480 response units (RU) by an amine coupling kit. The antibodies (2F4 and 1G1) were diluted in HBS-EP buffer were slowly passed over the chip with $50 \mu \mathrm{L} / \mathrm{min}$ for 5 min, respectively, and subsequently HBS-EP buffer injected over the chip to monitor the dissociation phase for $4 \mathrm{~min}$. The sensor chips were regenerated with Glycine solution $(\mathrm{pH}$ 3.0) following the dissociation phase. For each analyte passed over the chip, the specific responses from the antigen flow channel could subtract non-specific responses for the control flow channel. The fitted saturation binding curves were plotted based on concentrations of analyte for equilibrium binding responses to calculate KD.

Purified anti-NGAL MAbs was analyzed in $12 \%$ SDSPAGE under non-reducing conditions and reducing conditions. Briefly, sample was mixed with $5 \mathrm{x}$ non-reducing buffer or $5 \mathrm{x}$ protein loading buffer and loaded onto $12 \%$ SDS-PAGE. The specificity of anti-NGAL MAbs was determined by Western Blot. The NGAL proteins were done to $12 \%$ SDS-PAGE, then adsorbed onto PVDF membrane that activated by soaking in methanol for $15 \mathrm{~s}$, and then subjected to the electrophoresis conditions in $100 \mathrm{~V}$ for $2 \mathrm{~h}$. After blocking in Tris- $\mathrm{HCl}$ buffer with $1 \%$ Tween-20 solution (TBST) containing $5 \%$ skimmed milk at RT for $2 \mathrm{~h}$, the membrane was incubated with mouse anti-NGAL MAbs as the primary antibodies at $4{ }^{\circ} \mathrm{C}$. The next day, membrane was washed with TBST and incubated with anti-mouse conjugated HRP IgG in the dark for $1.5 \mathrm{~h}$ at RT. Finally, the membrane was visualized by the Western blot detection system of enhanced chemiluminescence (ECL).

\section{Competitive enzyme-linked immunosorbent assays (cELISA)}

Two MAbs were tested for the ability to recognize to unique epitopes on NGAL by cELISA. MAb was conjugated with HRP by using HRP Antibody Labeling Kit (Shanghai YSRIBIO industrial co., LTD), and the working concentration of which was tested through direct ELISA. 96-well Microtitre plates were coated with $2 \mu \mathrm{g} /$ mL of NGAL antigenin overnight at $4{ }^{\circ} \mathrm{C}$, then unlabeled MAb $(0.2 \mu \mathrm{g} /$ well, $2 \mu \mathrm{g} /$ well $)$ was competitively bound with the optimal dilution ratio of HRP labeled MAb and incubated for $1 \mathrm{~h}$ at $37^{\circ} \mathrm{C}$. The enzymatic reaction was appeared with hydrogen peroxide by substrate 3,3',5,5'Tetramethylbenzidine (TMB) and stopped by $2 \mathrm{M}$ sulfuric acid to all wells. The absorbance (OD450 nm) was determined by Bio-Rad microplate reader (Bio-Rad Laboratories, Inc). The blocking effects of MAbs was calculated by using the following equation: $100 \times\left[1-\mathrm{OD}_{450} \mathrm{~nm}\right.$ of (HRP-MAb $+\mathrm{MAb}) / \mathrm{OD}_{450} \mathrm{~nm}$ of HRP-MAb]. Two MAbs recognized different epitopes if blocking effects observed more than $40 \%$.

\section{Conjugation of EU-NPS}

The Anti-NGAL monoclonal antibody $1 \mathrm{G} 1$ and 2F4 were covalently conjugated to EU-NPS with standard procedure of Bangs Laboratories. Briefly, $100 \mu \mathrm{L}$ EUNPS were added to $900 \mu \mathrm{L} 0.05 \mathrm{M}$ MES (pH 7.0) and dispersed by ultrasound, vibrated for $15 \mathrm{~min}$ at RT in the presence of $0.08 \mathrm{M} \mathrm{N}$-hydroxysulfosuccinimide (NHS) and 0.05 M 1-(3-Dimethylaminopropyl)-3-ethylcarbodiimide hydrochloride (EDC). The activated EUNPS ware washed with coupling buffer $(0.05 \mathrm{mM}$ $\mathrm{H}_{3} \mathrm{BO}_{3}, 0.04 \mathrm{mM} \mathrm{Na} \mathrm{B}_{4} \mathrm{O}_{7}, \mathrm{pH}$ 7.5) and reacted with $0.3 \mathrm{mg}$ antibody for $2.5 \mathrm{~h}$ at RT. The europiumconjugated compound was incubated in $1000 \mu \mathrm{L}$ blocking buffer (10\% BSA, $20 \%$ tween-20, $0.05 \mathrm{M}$ Tris- $\mathrm{HCl})$ for $1 \mathrm{~h}$, added to $1000 \mu \mathrm{L}$ stock solutions (10\% BSA, $20 \%$ trehalose, $20 \%$ tween- $20,0.05 \mathrm{M}$ Tris- $\mathrm{HCl}$ ) to store at $4^{\circ} \mathrm{C}$.

\section{The development of LFIA}

The LFIA strips were consisted of nitrocellulose membrane, conjugate pad, sample pad and absorbing pad. The glass fiber membranes were soaked in the blocking buffer ( $20 \%$ trehalose, $10 \%$ BSA, $20 \%$ tween-20, $0.05 \mathrm{M}$ Tris, $3.2 \mathrm{mM}$ EDTA.Na 2 , pH 8.6) for $1.5 \mathrm{~h}$. The concentration of $1 \mathrm{mg} / \mathrm{mL}$ MAbs (2F4 or 1G1) was coated on the test line (TL) of nitrocellulose membrane, and goatanti-mouse IgG $1 \mathrm{mg} / \mathrm{mL}$ was coated on the same $\mathrm{NC}$ membrane at a distance of $4 \mathrm{~mm}$ to form a quality control line $(\mathrm{CL})$, the spray volume of dispenser instrument 
was set at $1 \mu \mathrm{L} / \mathrm{cm}$. The membrane and glass fiber mat were dried for $48 \mathrm{~h}$ at $45^{\circ} \mathrm{C}$ before tested. The different EU-NPS-1G1 and EU-NPS-2F4 conjugate particles were coated on the conjugate pad, and fluorescence signal was measured by immunofluorescent analyzer (Guangzhou Labsim Biotech Co., Ltd).

\section{Urine sample collection and patients}

The total of 83 Human urine samples from AKI patients were harvested from Affiliated Hospital of Jilin Medical University. The ethical guidelines were strictly complied in the experiment, was provided by the Affiliated Hospital of Jilin Medical University (No.2018-LW029). All subjects received oral and in written informed consent in Chinese for the study of urine samples. All experiments were performed in accordance with the Declaration of Helsinki Ethical Principles. The average age of patients was 62 years ranging from 20 to 80 years who were not infected by COVID-19 and AKI stage 1-3 was classified according to Kidney Disease Improving Global Outcomes AKI criteria[14]. Urine samples were collected for NGAL analysis up to $12 \mathrm{~h}$ before AKI was diagnosed and at frequent intervals after operation at various time points $(12,24,48 \mathrm{~h})$. For minimize potential confounding factors, urine samples were analyzed rapidly at clinical chemistry laboratory including urine biochemistry (total protein concentrations $<1 \mathrm{~g} / \mathrm{dL}$, urea $<12 \mathrm{~g} / \mathrm{dL}$, glucose $<1 \mathrm{~g} / \mathrm{dL}$, Urine Creatinine $<1 \mathrm{~g} /$ $\mathrm{dL}$, albumin $<2.5 \mathrm{~g} / \mathrm{dL}, \mathrm{pH} 4.5-9.0$ ) and carried out in duplicates. Within $30 \mathrm{~min}$ of samples collection, they were centrifuged at $3000 \mathrm{rpm}$ at $4^{\circ} \mathrm{C}$ for $15 \mathrm{~min}$. A minimum of $100 \mu \mathrm{L}$ of supernatant was dispensed into sterile containers and stored at $-80^{\circ} \mathrm{C}$ for further analyses, to avoid repeated freeze-thaw cycles.

The measurement of NGAL levels was performed using ARCHITECT urine NGAL reagent Kit (Lisnamuck, Longford, Co. Longford, Ireland) utilized a noncompetitive, sandwich format with chemiluminescent signal detection. Urinary NGAL was recognized by antiNGAL antibody which was covalently attached to paramagnetic particles in microparticle reagent, and the conjugate of second anti-NGAL antibody associated with acridinium. Following the manufacturer's instructions, the calibration assay was carried out in the range of 0 $1500 \mathrm{ng} / \mathrm{mL}$ and the concentration of NGAL was measured.

\section{Clinical sample testing and analysis}

The serial concentrations of NGAL standards antigen $(10,50,100,200,400,800,1500,2000$ and $3000 \mathrm{ng} / \mathrm{mL})$ were prepared by using FBS to strengthen specific reaction of bioconjugate, each concentration done three replicates. After the clinical samples were added onto the sample pads, the results of fluorescence intensity on the
$\mathrm{T}$ line $(\mathrm{HT})$ and the $\mathrm{C}$ line $(\mathrm{HC})$ were recorded by the reader. Quantitative detection was completed by the $\mathrm{HT} / \mathrm{HC}$ ratio to effectively eliminate strips ( $\mathrm{T}$ and $\mathrm{C}$ ) difference and matrsample standard matrix effects[15]. The standard curve was plotted against each concentration of NGAL and HT/HC ratio.

\section{Statistical analysis}

The Passing-Bablok regression analysis and BlandAltman plot were performed by analysis of variance (ANOVA) of MedCalc and SPSS 17.0 software. All data were showed as mean value with standard deviation $($ mean \pm S.D. $)$.

\section{Results}

Expression and purification of recombinant NGAL protein The pSecTag2A-NGAL recombinant plasmid was transfected into $\mathrm{CHO}$ cells. The NGAL- $6 \times$ His protein mainly expressed in cell supernatant and subsequently purified by Ni Sepharose. The purified recombinant NGAL protein was obtained about $95 \%$ purity and analyzed by SDS-PAGE with molecular approximate weight of $23.7 \mathrm{kDa}$ (Fig. $1 \mathrm{~A}$ ). Western blot also confirmed the recombinant protein NGAL expression and purification (Fig. 1B).

\section{Generation of MAbs}

First, we compared the effects of DC voltage on cell membrane perforation under different electric field intensities, and the pulse amplitude was $400 \mathrm{~V}, 450 \mathrm{~V}, 500$ and $550 \mathrm{~V}$ respectively, so as to optimize the electric fusion scheme. According to previous reports, cell concentration has a significant impact on fusion efficiency[16]. The mixed suspension of isolated spleen cells and SP2/0 myeloma cells was transferred into the fusion chamber at different concentrations of approximately $2 \times 10^{6}, 2 \times$ $10^{7}$, and $2 \times 10^{8}$ cells $/ \mathrm{mL}$. The fusion efficiency was the highest at $450 \mathrm{~V} \mathrm{DC}$, and the optimal cell concentration was $2 \times 10^{7}$ cells $/ \mathrm{mL}$ (Fig. 2).

\section{Characterization of MAbs}

The MAbs were purified by Protein A column. The purified MAbs were separated by $12 \%$ SDS-PAGE, two bands with molecular weight $55 \mathrm{kDa}$ and $25 \mathrm{kDa}$ were observed under reducing condition. The clear bands of $170 \mathrm{kDa}$ were noted under non-reducing condition, which are the intact protein of 2F4 and 1G1(Fig. $3 \mathrm{~A}$ ). Western blot indicated that all MAbs specifically bind to human NGAL protein (Fig. 3B). After cell electrofusion and sub-cloning, the supernatants of hybridomas were detected by indirect ELISA with NGAL- $6 \times$ His and PCT$6 \times$ His to ensure antibodies specific binding to the NGAL. Two highly positive hybridomas (1G1, 2F4) with specific NGAL binding while without cross-reaction to 


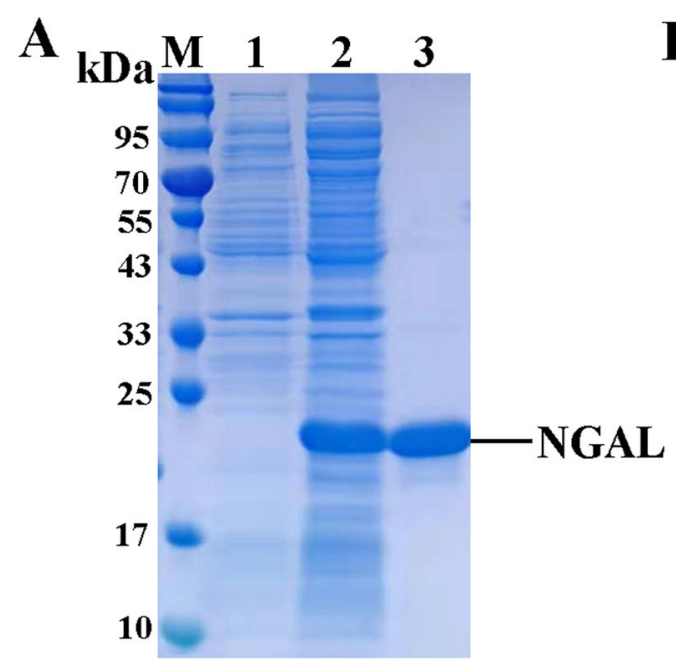

B
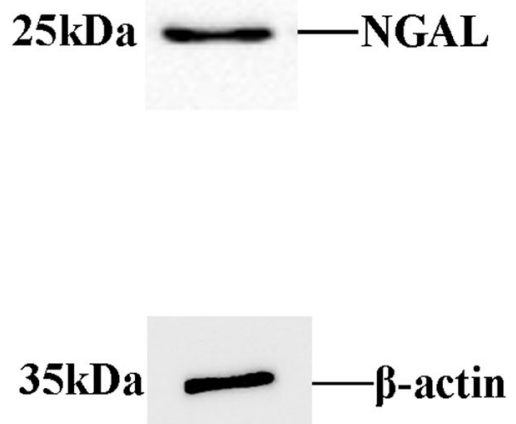

Fig. 1 Expression and purification of NGAL-6xHis. (A) Purification of NGAL-6xHis protein were appraised by SDS-PAGE, Lane M, protein marker; Lane 1, supernatant of $\mathrm{CHO}$ cell culture; Lane 2, supernatant of induced sample; Lane 3, purified protein. (B) Western blot analysis of NGAL-6xHis expression

PCT $-6 \times$ His were successfully selected for production and purification of MAbs (Fig. $3 \mathrm{C}$ ). To detect the affinity of two MAbs, the interaction between antibodies with different concentrations and NGAL protein was analyzed by BIAcore T200 system. The kinetic diagram showed that the affinity of $2 \mathrm{~F} 4$ and $1 \mathrm{G} 1$ were $4.5 \times 10^{-7}$ and $6.0 \times 10^{-7}$, respectively (Fig. 3D). The isotypes of those two MAbs which were detected by commercial kits were IgG1.The blocking rate of 2F4 and 1G1-HRP

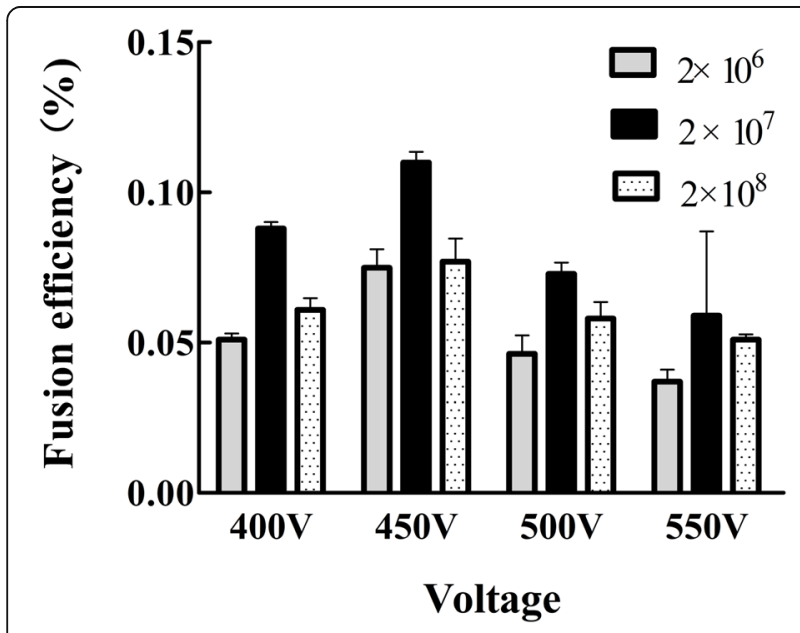

Fig. 2 Comparison of fusion efficiency using different the puncture pulse height. The fusion cells were seeded into 96-well plates at approximately $2 \times 10^{5}$ cells/well. A total of 480 wells was assessed for each condition. The calculated method of the fusion efficiency (\%): the total number of colonies in 480 wells were counted,then divided by the number of input B cells and multiplied by 100 . The columns represent the average fusion efficiency (\%) of 3

experiments, the error bars represent the SD pairing was $63 \%$ by cELISA detection, indicating that they recognized different epitopes.

\section{EU-NPS-LFIA Procedures}

Based on EU-NPS as labels and the sandwich-type immunoassay, the LFIA was established for detection of NGAL. MAb 2F4 was coated on nitrocellulose membrane and paired with EU-NPS-1G1 based on antibodies pairing in lateral flow immunochromatography platform. As schematically illustrated (Fig. 4), TL and CL of nitrocellulose membrane were coated with the MAbs 2F4 and goat anti-mouse IgG. EU-NPS-1G1 was labeled on the conjugate pad. The sample containing NGAL antigen migrated towards the conjugate pad to combine with EU-NPS-1G1 and form antigen-antibody complexes. Subsequently, the complexes were captured by $\mathrm{mAb} 2 \mathrm{~F} 4$ in T-line while migrating to form sandwich complexes. Excess complex was combined the goat antimouse IgG. Test strips were measured with a fluorescence detector after $15 \mathrm{~min}$.

\section{Performance evaluation}

The antibody pairs (2F4- labled1G1) as detector and capture antibodies were used to establish fluorescent immunochromatographic, and the analytical performances of EU-NPS-LFIA was evaluated by building the standard curve. The relative fluorescence intensity ratio(HT/HC) was increased with NGAL concentration. EU-NPS-1G1 showed reaction to mAb 2F4 (Fig. 5 A). The high-dose hook influence wasn't detected when concentration of antigen reached $3000 \mathrm{ng} / \mathrm{mL}$. The regression equation was exhibited as follows: $y=0.0012$ $x+0.0059\left(R^{2}=0.99\right)$, where $y$ represents the ratio of $\mathrm{HT} / \mathrm{HC}, \mathrm{x}$ represents the concentrations of NGAL 


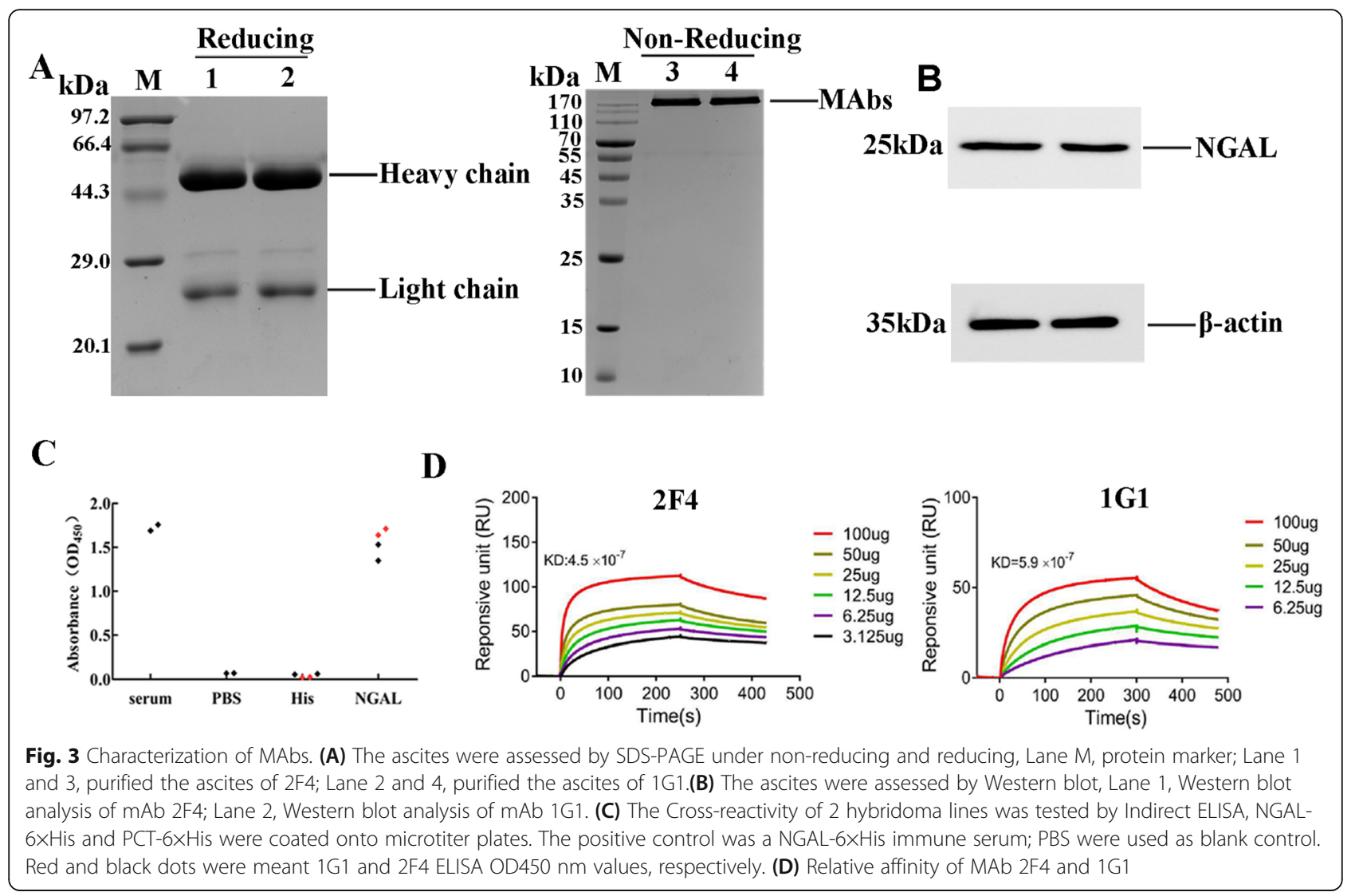

(Fig. 5B).The detection limit (LOD) was $0.36 \mathrm{ng} / \mathrm{mL}$ (3 times the standard deviation of the blank, $n=20$ ) calculated by the Clinical Laboratory Standards Institute (CLSI) Guideline EP17-A2, the NGAL concentration had linear relationship in the range of $1-1500 \mathrm{ng} /$ $\mathrm{mL}[17]$.

\section{Precision}

Recovery experiments of the intra-assay and interassay were performed to evaluate precision and reproducibility of immunological method. The different concentrations $(50,200$ and $800 \mathrm{ng} / \mathrm{mL}$ ) of NGAL standard substance were added to negative urine samples. The intra-assay precision was calculated

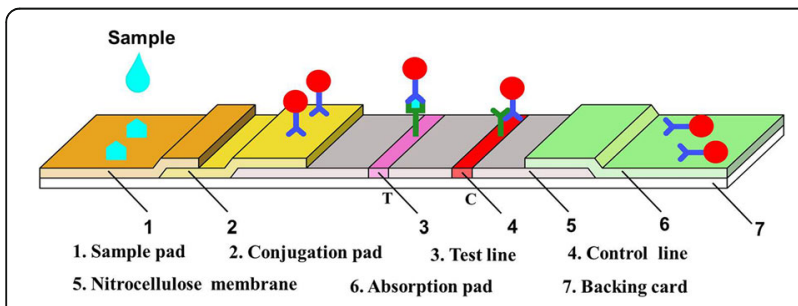

Fig. 4 Schematic description of fluorescence immunoassay system employed Europium-conjugated NGAL MAbs with three replicates at each spiked concentration in 1 day, and inter-assay precision was calculated with three replicates at each spiked concentration at every three days for fifteen days continuously[18]. The results were shown in Table 1 , the calculated intraassay coefficient of variation $(\mathrm{CV})$ ranged from 2.57 to $4.98 \%(n=10)$, lower than $10 \%$. The inter-assay $\mathrm{CV}$ ranged from 4.11 to $7.83 \%(\mathrm{n}=15)$, lower than $10 \%$ too.

Intra-assay and inter-assay precision were verified by two evaluator devices (Guangzhou Wondfo Biotech Co.,Ltd and Guangzhou Labsim Biotech Co., Ltd), and the result is eventually consistent (Supplement data). These results explained that the precision of the developed LFIA was a high level, and reproducibility was an acceptable level.

\section{Specificity}

The specificity of the test strips was evaluated by adding endogenous substances in normal and different concentrations urine samples, including creatinine, glucose and urea nitrogen. As shown in Table 2, the results indicated that all relative deviations (RD) was in the range of \pm $10 \%$, suggesting antigen-antibody interaction were stable and illustrating the specificity of test strips was acceptable toward NGAL. 

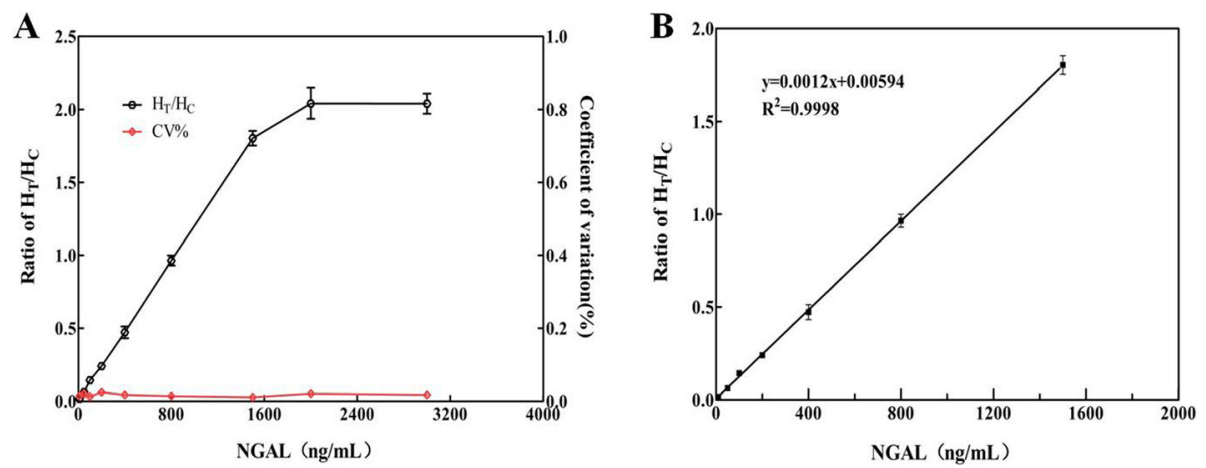

Fig. 5 Standard curves for NGAL. (A) The ratio of HT/HC, by antibody pairing in LFIA, the antibody pairs 2F4-labled1G1 ratio of HT/HC rose with increasing concentration of NGAL. (B) The standard curve of NGAL

\section{Clinical samples tests}

In order to appraise applicative competence of the NGAL based on EU-NPS-LFIA for determination of clinical samples, a total of 83 urine samples containing 26 low value samples (11-70 $\mathrm{ng} / \mathrm{mL}), 19$ median value samples (110-800 ng/mL), 38 high value samples (800$1740 \mathrm{ng} / \mathrm{mL}$ ), were measured on the ARCHITECT urine NGAL assay. The results of correlation coefficient $\left(\mathrm{R}^{2}\right)$ of the regression curve was $0.9829(p<0.01)$, indicating that the two detection methods had a significant linear relationship (where $\mathrm{x}$ represents concentrations of NGAL obtained by the ARCHITECT analyzer, y represents values measured by developed test strips) (Fig. 6). Thus, the developed EU-NPS-LFIA for determination of NGAL was very accurate in clinical testing.

\section{Discussion}

The EU-NPS-LFIA for detection of NGAL in human urine and diagnosis of AKI has been developed in our study. Current diagnosis of AKI is confirmed by the concentration of serum creatinine ( $\mathrm{sCr}$ ), which is steady unless at least $50 \%$ of damaged kidney function[19]. AKI developed in $89 \%$ of severe patients with COVID-19, and a majority of patients had predominantly oliguria when appears earlier than plasma Creatinine[20]. Biomarkers increased elevated levels at admission, which associated with increased mortality. NGAL is one of these biomarkers, levels of which may positive correlation with risk for mortality in COVID-19 hospitalized patients[21]. In AKI, several studies have discovered NGAL

Table.1 Reproducibility analysis of the EU-NPS-LFIA test strip by intra-assay and inter-assay precision

\begin{tabular}{|c|c|c|c|c|}
\hline \multirow{2}{*}{$\begin{array}{l}\text { NGAL } \\
\text { (ng/ } \\
\mathrm{mL} \text { ) }\end{array}$} & \multicolumn{2}{|c|}{ Intra-Assay Precision $(n=10)$} & \multicolumn{2}{|c|}{ Inter-Assay Precision $(n=15)$} \\
\hline & Mean \pm SD (ng/mL) & CV (\%) & Mean \pm SD (ng/mL) & CV (\%) \\
\hline 50 & $49.57 \pm 0.003$ & 4.98 & $51.28 \pm 0.037$ & 5.68 \\
\hline 200 & $199.18 \pm 0.009$ & 3.84 & $202.78 \pm 0.019$ & 7.83 \\
\hline 800 & $799.76 \pm 0.025$ & 2.57 & $801.68 \pm 0.039$ & 4.11 \\
\hline
\end{tabular}

concentration in urine is significantly associated with $\mathrm{sCr}$ concentration[22]. In recent years, various electrochemical and immunological methods have been developed for the detection of NGAL, instance of electrochemical determination, solid-phase proximity ligation assay and enzyme-free electrochemical immunoassay[23, 24]. However, these techniques require precise equipment, specialized personnel and professional interpretation of the results. Therefore, to develop an effective and convenient detection assay for NGAL concentration in the urine is critical for this disorder monitoring. The low efficiency of polyethylene glycol (PEG) fusion in conventional methods to causes difficulties in obtaining functional antibodies, we optimized electric fusion parameters that enabled enhancement of fusion efficiency to prepare of viable hybridomas, and obtained two anti-NGAL MAbs. MAbs are not only high affinity, but also directed towards different epitopes, used to establish high quality of diagnostic assays.

In recent years, many studies have been reported to develop several NGAL rapid diagnostic immunoassays, including the photoelectrochemical immunosensor and three electrochemical immunosensors, the solid-phase proximity ligation assay and lateral flow assay[25]. In one study, immunosensor has been made by NGAL capture antibodies immobilized to screen-printed-modified carbon electrode and labeled addition of secondary antibody against NGA to PB-NP-decorated g- $\mathrm{C}_{3} \mathrm{~N}_{4}$ nanosheets forming a sandwich on the SPCE[24]. The other study developed antibody against NGAL was immobilized on a screen printed electrode (SPCE) modified with electropolymerized aniline deposited on top of an electrosprayed graphene/poly-aniline (G/PANI)[25]. Two reports showed the LOD varied widely from $0.6 \mathrm{pg} / \mathrm{mL}$ to $21.1 \mathrm{ng} / \mathrm{mL}$, depending on the $\mathrm{g}-\mathrm{C}_{3} \mathrm{~N}_{4}$ nanosheets with $\mathrm{N}$ element enhanced electrocatalytic efficiency of the nanohybrids than graphene nanosheets, and the LOD of the NGAL assay varies depending on immunosensor, conjugated-complex and antibodies[26]. According to 
Table.2 The specificity study of the EU-NPS-LFIA with different interfering endogenous substances

\begin{tabular}{|c|c|c|c|c|}
\hline \multirow[t]{2}{*}{ Interfering Substance } & \multicolumn{2}{|c|}{ NGAL (27.64ng/mL) } & \multicolumn{2}{|c|}{ NGAL (53.72ng/mL) } \\
\hline & Value & RD (\%) & Value & RD (\%) \\
\hline control & $0.037 \pm 0.002$ & 0.54 & $0.069 \pm 0.003$ & 2.35 \\
\hline Creatinine(10 mg/mL) & $0.035 \pm 0.008$ & -4.55 & $0.067 \pm 0.009$ & -2.06 \\
\hline glucose(10 mg/mL) & $0.036 \pm 0.007$ & -2.55 & $0.071 \pm 0.006$ & 3.83 \\
\hline urea nitrogen(100 mg/mL) & $0.036 \pm 0.004$ & 2.72 & $0.064 \pm 0.008$ & -5.98 \\
\hline
\end{tabular}

Note: $\mathrm{RD}$ = (Value-Standard value) / Standard value

those studies, we enlightened that sensitivity of LFIA could be improved by basing on different fluorescence nanoparticles mentioned in the preamble section. The high sensitivity nanoparticles labeled in LFIA as fluorescent probes has been continually researched over past decades, gold nanoparticles are the most widely used, but the application of the lateral flow tests based on traditional labels is limitedfor there poor identification and weaker the signal[27]. Currently there are antibodies available for the development of NGAL have been applied to different platforms for NGAL detection, but not available in LFIA based on EU-NPS labels experimented on the detection of NGAL in addition to UCP technology-based lateral flow assay [28, 29].

Fluorescence immunoassays have advantange in various detection fields, especially in mature quantum dots, that sensitivity was influenced by the MAbs and fluorescent materials, and could greatly improve by EU-NPS and specific MAbs to use the fluorescent probes[30]. The EU-NPS were applied to fluorescence LFIA strips had matured in the detection field, and enhanced several advantages of LFIA for assay sensitivity, specificity and stability[31]. Due to excellent properties of the EU-NPS that the limit of detection for NGAL in this method was $0.36 \mathrm{ng} / \mathrm{mL}$, while the mean urine NGAL levels was

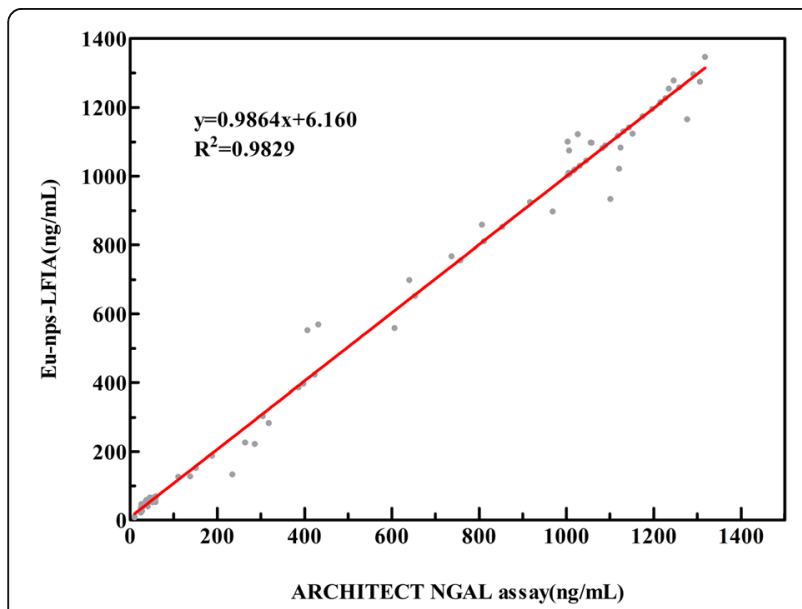

Fig. 6 Comparison of EU-NPS-LFIA with ARCHITECT urine assay estimated correlation of the results for NGAL clinical test about $7.0 \mathrm{ng} / \mathrm{mL}$ in healthy individuals[32]. The developments and application about the EU-NPS-LFIA of NGAL are still in initial phase, this assay need to test NGAL of serum and urine samples with COVID- 19 patients for which improvement in the treatment in the future of works.

\section{Conclusions}

In the study, we successfully got two mouse anti-NGAL MAbs (2F4, 1G1) and were labeled with EU-NPS to establish the lateral flow immune technique. The EU-NPSLFIA was found to detect NGAL in a wide range of 1$3000 \mathrm{ng} / \mathrm{mL}$ within $15 \mathrm{~min}$, the detection sensitivity reached $0.36 \mathrm{ng} / \mathrm{mL}$. These anti-NGAL MAbs could be reliability utilized in fluorescence LFIA of NGAL detection in the urine samples, so that it should be applicable in the AKI diagnosis.

\section{Supplementary information}

The online version contains supplementary material available at https://doi. org/10.1186/s12882-021-02493-w.

\section{Additional file 1 zip}

\section{Abbreviations}

COVID-19: Coronavirus Infection Disease 2019; AKl: Acute kidney injury; SCr: serum creatinine; NGAL: neutrophil gelatinase-associated lipocalin; LFIA: Lateral flow immunoassays; EU-NPS: europium nanoparticles;

ELISA: enzyme-linked immunosorbent assay; MAbs: monoclonal antibodies

\section{Acknowledgements}

Not applicable.

Authors' contributions

HYW designed the experiments; MLY, YWN, HL and LL performed study planning, data analysis, manuscript drafting and manuscript review.LT, YD and $\mathrm{CMH}$ revised the manuscript.All authors gave intellectual input to the manuscript and approved final version.

\section{Funding}

The authors disclosed receipt of the following financial support for the research, authorship, and/or publication of this article:This work was supported by the 'Research and Development of Industrial Technology' Program of Jilin Province, PR China (grant nos. 20180623045TC and 20170204005YY), National Natural Science Foundation of China (no. 21827812) and National Training Program of Innovation and Entrepreneurship for Undergraduates (nos. 201913706017 and 202013706002). 


\section{Availability of data and materials}

The datasets used and/or analyzed during the current study are available from the corresponding author on reasonable request.

\section{Declarations}

\section{Ethics approval and consent to participate}

The study was performed on the basis of institutional ethical guidelines, approved by the Affiliated hospital of Jilin Medical University in China. All procedures were followed the principles Declaration of Helsinki, informed consent was obtained from all subjects.

\section{Consent for publication}

Not applicable.

\section{Competing interest}

The authors declare that they have no conflict of interest.

\section{Author details}

'Jilin Collaborative Innovation Center for Antibody Engineering, Jilin Medical University, 132013 Jilin, PR China. ${ }^{2}$ Academy of laboratory, Jilin Medical University, 132013 Jilin, PR China.

Received: 15 March 2021 Accepted: 2 August 2021

Published online: 14 January 2022

\section{References}

1. Zheng X, Zhao Y, Yang L: Acute Kidney Injury in COVID-19: The Chinese Experience. Seminars in nephrology 2020, 40(5):430-442.

2. Mandelbaum T, Scott D, Lee J, Mark R, Malhotra A, Waikar S, Howell M, Talmor D: Outcome of critically ill patients with acute kidney injury using the Acute Kidney Injury Network criteria. Critical care medicine 2011, 39(12): 2659-2664.

3. Al-Hwiesh A, Mohammed A, Elnokeety M, Al-Hwiesh A, Al-Audah N, Esam S, Abdul-Rahman I: Successfully treating three patients with acute kidney injury secondary to COVID-19 by peritoneal dialysis: Case report and literature review. Peritoneal dialysis international 2020, 40(5):496-498.

4. Shabaka A, Rovirosa-Bigot S, Guerrero Márquez C, Alonso Riaño M, Fernández-Juárez G: Acute kidney injury and nephrotic syndrome secondary to COVID-19-associated focal segmental glomerulosclerosis. Nefrologia 2021.

5. Gabbard W, Milbrandt E, Kellum J: NGAL: an emerging tool for predicting severity of AKI is easily detected by a clinical assay. Critical care 2010, 14(4): 318.

6. Zuk R, Ginsberg V, Houts T, Rabbie J, Merrick H, Ullman E, Fischer M, Sizto C, Stiso S, Litman D: Enzyme immunochromatography-a quantitative immunoassay requiring no instrumentation. Clinical chemistry 1985, 31 (7): 1144-1150.

7. Juntunen E, Myyryläinen T, Salminen T, Soukka T, Pettersson K: Performance of fluorescent europium(III) nanoparticles and colloidal gold reporters in lateral flow bioaffinity assay. Analytical biochemistry 2012, 428(1):31-38.

8. Swanson C, D'Andrea A: Lateral flow assay with near-infrared dye for multiplex detection. Clinical chemistry 2013, 59(4):641-648.

9. Chen Y, Fu Q, Xie J, Wang H, Tang Y: Development of a high sensitivity quantum dot-based fluorescent quenching lateral flow assay for the detection of zearalenone. Analytical bioanalytical chemistry 2019, 411(10): 2169-2175.

10. Zhang F, Zou M, Chen Y, Li J, Wang Y, Qi X, Xue Q: Lanthanide-labeled immunochromatographic strips for the rapid detection of Pantoea stewartii subsp. stewartii. Biosensors bioelectronics 2014, 51:29-35.

11. Nankoberanyi S, Mbogo G, LeClair N, Conrad M, Tumwebaze P, Tukwasibwe S, Kamya M, Tappero J, Nsobya S, Rosenthal P: Validation of the ligase detection reaction fluorescent microsphere assay for the detection of Plasmodium falciparum resistance mediating polymorphisms in Uganda. Malaria journal 2014, 13:95

12. Xu H, Dong Y, Guo J, Jiang X, Liu J, Xu S, Wang H: Monoclonal antibody production and the development of an indirect competitive enzyme-linked immunosorbent assay for screening T-2 toxin in milk. Toxicon 2018, 156:1-6.

13. Kato M, Sasamori E, Chiba T, Hanyu Y: Cell activation by CpG ODN leads to improved electrofusion in hybridoma production. Journal of immunological methods 2011, 373:102-110.
14. Nephron KJ: KDIGO clinical practice guidelines for acute kidney injury. 2012, 120(4):C179-c184.

15. Huang $X$, Aguilar Z, Xu H, Lai W, Xiong Y: Membrane-based lateral flow immunochromatographic strip with nanoparticles as reporters for detection: A review. Biosensors bioelectronics 2016, 75:166-180.

16. Weeratna R, Comanita L, Davis H: CPG ODN allows lower dose of antigen against hepatitis B surface antigen in BALB/c mice. Immunology cell biology 2003, 81(1):59-62.

17. Tong Q, Chen B, Zhang R, Zuo C: Standardization of clinical enzyme analysis using frozen human serum pools with values assigned by the International Federation of Clinical Chemistry and Laboratory Medicine reference measurement procedures. Scandinavian journal of clinical laboratory investigation 2018, 78:74-80.

18. Huang D, Ying H, Jiang D, Liu F, Tian Y, Du C, Zhang L, Pu X: Rapid and sensitive detection of interleukin-6 in serum via time-resolved lateral flow immunoassay. Analytical biochemistry 2020, 588:113468.

19. Shapiro N, Trzeciak S, Hollander J, Birkhahn R, Otero R, Osborn T, Moretti E, Nguyen H, Gunnerson K, Milzman D et al: The diagnostic accuracy of plasma neutrophil gelatinase-associated lipocalin in the prediction of acute kidney injury in emergency department patients with suspected sepsis. Annals of emergency medicine 2010, 56(1):52-59.e51.

20. Luther T, Bülow-Anderberg S, Larsson A, Rubertsson S, Lipcsey M, Frithiof R, Hultström M: COVID-19 patients in intensive care develop predominantly oliguric acute kidney injury. Acta anaesthesiologica Scandinavica 2021, 65(3): 364-372.

21. Abers $\mathrm{M}$, Delmonte $\mathrm{O}$, Ricotta E, Fintzi J, Fink D, de Jesus $\mathrm{A}$, Zarember $\mathrm{K}$, Alehashemi $\mathrm{S}$, Oikonomou V, Desai J: An immune-based biomarker signature is associated with mortality in COVID-19 patients. JCl insight 2021, 6(1).

22. Wagener G, Jan M, Kim M, Mori K, Barasch J, Sladen R, Lee H: Association between increases in urinary neutrophil gelatinase-associated lipocalin and acute renal dysfunction after adult cardiac surgery. Anesthesiology 2006, 105(3):485-491.

23. Kannan P, Tiong H, Kim D: Highly sensitive electrochemical determination of neutrophil gelatinase-associated lipocalin for acute kidney injury. Biosensors bioelectronics 2012, 31(1):32-36.

24. Zhang F, Zhong H, Lin Y, Chen M, Wang Q, Lin Y, Huang: A nanohybrid composed of Prussian Blue and graphitic CN nanosheets as the signal-generating tag in an enzyme-free electrochemical immunoassay for the neutrophil gelatinase-associated lipocalin. Mikrochimica acta 2018, 185(7):327.

25. Yukird J, Wongtangprasert T, Rangkupan R, Chailapakul O, Pisitkun T, Rodthongkum N: Label-free immunosensor based on graphene/polyaniline nanocomposite for neutrophil gelatinase-associated lipocalin detection. Biosensors bioelectronics 2017, 87:249-255.

26. Gong Y, Li M, Wang Y: Carbon nitride in energy conversion and storage: recent advances and future prospects. ChemSusChem 2015, 8(6):931-946.

27. Chen A, Yang S: Replacing antibodies with aptamers in lateral flow immunoassay. Biosensors bioelectronics 2015, 71:230-242.

28. Li H, Mu Y, Yan J, Cui D, Ou W, Wan Y, Liu S: Label-free photoelectrochemical immunosensor for neutrophil gelatinase-associated lipocalin based on the use of nanobodies. Analytical chemistry 2015, 87(3): 2007-2015.

29. Lei L, Zhu J, Xia G, Feng H, Zhang H, Han Y: A rapid and user-friendly assay to detect the Neutrophil gelatinase-associated lipocalin (NGAL) using upconverting nanoparticles. Talanta 2017, 162:339-344.

30. Yeo S, Bao D, Seo G, Bui C, Kim D, Anh N, Tien T, Linh N, Sohn H, Chong C et al: Improvement of a rapid diagnostic application of monoclonal antibodies against avian influenza $\mathrm{H7}$ subtype virus using Europium nanoparticles. Scientific reports 2017, 7(1):7933.

31. Chen E, Xu Y, Ma B, Cui H, Sun C, Zhang M: MonascusCarboxylFunctionalized, Europium Nanoparticle-Based Fluorescent Immunochromatographic Assay for Sensitive Detection of Citrinin in Fermented Food. Toxins 2019, 11(10).

32. Bolignano D, Coppolino G, Campo S, Aloisi C, Nicocia G, Frisina N, Buemi M: Neutrophil gelatinase-associated lipocalin in patients with autosomaldominant polycystic kidney disease. American journal of nephrology 2007, 27(4):373-378

\section{Publisher's Note}

Springer Nature remains neutral with regard to jurisdictional claims in published maps and institutional affiliations. 